\title{
Research on the Innovation of Supply Chain Management Mode of Cross-Border B2B Foreign Trade Export Enterprises in the Context of Big Data
}

\author{
ChuJia Liu, Dr. Nolan Guillao \\ University of the Cordilleras, Baguio City, Philippines
}

\begin{abstract}
:
With the continuous advancement of global economic integration, the influence of big data on cross-border B2B foreign trade export companies is increasing. Every cross-border B2B foreign trade export company needs to deal with increasingly fierce market competition, and cross-border $\mathrm{B} 2 \mathrm{~B}$ foreign trade export companies want to gain a competitive advantage, which it is necessary to actively introduce big data technology to innovate the management model of cross-border B2B foreign trade export enterprises. The managers of cross-border B2B foreign trade export enterprises must innovate decision-making concepts in a timely manner, collect and analyze big data, and make them a foreign trade enterprise. Meanwhile we need to pay attention to the introduction of high-quality professional data talents. This article first puts forward the concept and main characteristics of big data, which clarifies the various problems faced by foreign trade export enterprises since entering the era of big data. With the help of supply chain management mode, we need to innovates the management mode of cross-border B2B foreign trade export enterprises and actively applies big data technology and supply Chain management which promotes the healthy development strategy of foreign trade export enterprises and improves the core competitiveness of foreign trade export enterprises.
\end{abstract}

Keywords: Big data, Cross-border B2B foreign trade export enterprises, Supply chain management model innovation.

\section{INTRUDUCTION}

The era of big data has an increasing impact on various sectors of the national economy. If foreign trade companies want to have a competitive advantage, they need to master effective market information and a large amount of data. Therefore, it is necessary to actively introduce 
big data technology to innovate the management mode of foreign trade enterprises in order to adapt to the needs of the developing times. The managers of foreign trade enterprises should innovate decision-making concepts in time, and have implement the public decision-making operation mode, and collect and analyze big data, which they can provide greater help for the development of foreign trade enterprises. Currently, they are sorting out and mining big data information, and apply it to the management of cross-border B2B foreign trade export enterprises, which will greatly enhance the competitiveness of foreign trade enterprises.

\section{A DEFINITION OF THE CONCEPT OF BIG DATA}

In March 2012, the Obama administration launched the "Big Data Research and Development Initiative", which defined big data as "the new oil of the future." The United States is the first country to emerge the concept of "big data", and McKinsey is the first person to propose the "big data era". He believes that the current data technology has been widely used in all fields of society and plays an important role in people's production and life. The data content that cannot be processed by conventional software tools is called big data [1]. In layman's terms, big data is the use of traditional IT technology to process data that cannot be processed and analyzed.

According to the definition of Wikipedia, Big Data, also known as huge data, which refers to the massive, that high growth rate and diversified information assets of requiring new processing models to have stronger decision-making power, insight, and process optimization capabilities. . The concept of "Big Data" was first proposed by Victor Meyer Schönberger and Kenneth Cukje in the compilation of "Big Data Era", which refers to the use of all data instead of the shortcut of random analysis (sampling survey) Perform analysis and processing. Big data has $4 \mathrm{~V}$ characteristics, namely Volume (large), Velocity (high speed), Variety (diversity), value (value).

The strategic significance of big data technology is not to master huge data information, but to professionally process these meaningful data. In other words, if big data is compared to an industry, then the key to profitability of this industry lies in improving the "processing capability" of data and realizing the "value-added" of data through "processing". Big data has been regarded as an asset, a wealth, and a value that can be measured and calculated. Those who gain big data win the world, is a judgment firmly believed by some change makers in the era of big data.

The salient features of big data are reflected in four aspects: One is large data volume (Volume). The starting unit of measurement for big data is at least P (1000 T), E (1 million T), 
or Z (1 billion T). second is many types (Variety), including web logs, audio, video, pictures, geographic location information, etc., multiple types of data put forward higher requirements for data processing capabilities. Third is low value density (Value). For example, with the widespread application of the Internet of Things, information perception is everywhere and information is massive, but the value density is low [2]. How to complete the value "purification" of data more quickly through powerful machine algorithms? Problems to be solved urgently in the era of big data. Four is Fast speed and high timeliness (Velocity) this is the most significant feature that distinguishes big data from traditional data mining. The existing technical architecture and route can no longer efficiently process such a large amount of data, and for relevant organizations, if the huge investment in collecting information cannot be processed in a timely manner to feedback effective information, it will be more than a loss. It can be said that the era of big data poses new challenges to human data controlling ability, and also provides unprecedented space and potential for people to gain deeper and comprehensive insights.

\section{OPPORTUNITIES BROUGHT TO FOREIGN TRADE EXPORT ENTERPRISES IN THE ERA OF BIG DATA}

Due to the uniqueness of big data itself, which brings great convenience to our foreign trade companies, it also brings more challenges to our foreign trade companies. As to the diversified characteristics of big data, foreign trade companies need to accept a large amount of unstructured data in addition to the information obtained through traditional channels. But the collection and sorting of these unstructured data is still a huge challenge for enterprises. In the context of accelerating economic globalization, it is no easy task for companies how to effectively process large amounts of data, conduct real-time and effective analysis, and respond to changing market conditions in a timely manner. In addition to a large amount of corporate information, the massive data collected by an enterprise also includes a large amount of customer information, such as customer personal information. How to properly keep customer privacy [3]. How to properly keep a series of security issues such as customer privacy, commercial secrets, and data backup is also a problem that requires considerable consideration for major companies.

3.1 The Processing and Analysis of Big data is becoming the Node of a New Generation of Information Technology Fusion Applications

Mobile Internet, Internet of Things, social networking, digital home, e-commerce, and so on which are the application forms of the new generation of information technology, and these applications continue to generate big data. 
3.2 The Use of Big Data Will Become a Key Factor in Improving the Core Competitiveness of Foreign Trade Export Enterprises

With the gradual emergence of the characteristics of quantification, diversification, rapidness, value of big data, and data assets have gradually become the core competitiveness of modern business society, and the importance of big data to industry users has become increasingly prominent.

Mastering data assets and making intelligent decision-making have become the key to an enterprise's emergence [4]. Therefore, more and more companies are beginning to attach importance to the strategic layout of big data and redefine their core competitiveness. Retail, e-commerce, consumer goods, communications, financial services and other industries are currently relatively mature areas for big data applications. Users can make intelligent decisions about services and marketing by mining and analyzing consumer interests, needs, purchase motivation, and brand emotions and loyalty; and provide customers better serve by analyzing and mining communication and financial activity records, they can expand their business scientifically.

The advantages of trade entities can be a major driving force for economic and trade development. As a major information carrier, data is a major driving force for companies to improve their efficiency.

At the national level, huge data resources can improve the country's comprehensive competitiveness. Big data has brought unprecedented development opportunities for foreign trade export enterprises, and indirectly improved the competitiveness of foreign trade export enterprises which these will become a major driving force for the development of international economic and trade, and then promote the development of world trade [5].

3.3 Big Data Resources have become an Important Strategic Resource for Export Foreign Trade Companies

In the Internet age, the meaning of "resources" is undergoing great changes, which it no longer only refers to some visible and tangible entities such as coal, petroleum, and minerals. "Big data" is also evolving into inaccessibility strategic resources. The Internet and the Internet of Things are generating large amounts of data every day. These huge data resources provide people with the possibility to understand the world and foreign trade export markets based on data [6]. Big data has been regarded as an asset, a wealth, and a value that can be measured and 
calculated. Those who gain big data win the world, is a judgment firmly believed by some change makers in the era of big data.

\subsection{Big Data Enriches the Content of Foreign Trade and Export Trade}

In the context of the era of big data, in international trade, if a country or company can grasp the information of market positioning analysis, consumer behavior analysis, and producer supply behavior analysis, the effectiveness of its market decisions and forecasts can be greatly improved. Therefore, many foreign trade export companies have invested in the ranks of database collection and analysis, and big data is also developing in the direction of industrialization. Many large multinational foreign trade export companies spend a lot of cost on data collection and purchase before making market analysis and product positioning decisions, which has also become a component of the cost of goods. Digital information trade has become an indispensable part of international trade [7]. If foreign trade export companies can make good use of this information, they can stand out in a highly competitive market environment. At present, most of my country's foreign trade export companies have invested in analyzing and collecting data, making big data move toward the trend of industrialization. It is precisely because of this that it poses new challenges to the content of international trade.

\subsection{Big Data Simplifies the Process of Foreign Trade Export}

Big data integrates the logistics industry. Before commodity sales, foreign trade export companies usually sell semi-finished products to other countries, and then these foreign trade export companies implement value-added processes before exporting to other companies. Under economic globalization, all major companies need to clarify the role of big data and develop a model that uses more convenient and efficient steps to use big data to improve the logistics industry.

\subsection{Big Data Brings New Risks to Foreign Trade and Export Trade}

As a symbol, big data contains technical barriers to extract data and information. As instant and fast information, big data's high-speed liquidity facilitates trade circulation and shortens the distance between trading entities. The risk of spreading trade information or maliciously grabbing by trade opponents will bring unpredictable trade losses. In the context of big data, trade security should be the focus of international trade theory.

\section{CROSS-BORDER B2B FOREIGN TRADE EXPORT COMPANIES FACE MANY DIFFICULTIES IN THE ERA OF BIG DATA}


Entering the era of big data, higher requirements are put forward on foreign trade export enterprises, and the amount of information presented in the era of big data is innumerable. While introducing structured and unstructured data, the production and operation activities of cross-border B2B foreign trade export enterprises must realize innovation and reform in time to adapt to the characteristics of the data age [8].

In addition, with the rapid development of information technology, every cross-border B2B foreign trade export company must achieve transformation and upgrading as soon as possible, which make full use of the development information brought by big data, correctly evaluate its own advantages and disadvantages, and clarify the future development direction in order to cope with the current fierceness. Market competition, the era of big data makes the development of cross-border B2B foreign trade export enterprises face the following problems.

\subsection{Difficulties in Processing Different Types of Data}

Since entering the era of big data, foreign trade export companies not only continue to use traditional means to obtain a large amount of structured information, but also use complex social networks and e-commerce to obtain a large number of unstructured data such as pictures, sounds, videos, and logs. Chemical data cannot be analyzed and processed in a timely manner, which will inevitably restrict the healthy development of enterprises [9]. Furthermore, realizing the processing and integration of structured data, semi-structured data, and unstructured data is also a major difficulty facing enterprises.

\subsection{Research Data Processing is not Timely Enough}

With the rapid advancement of economic integration, enterprises are responding to fierce market competition. Only by timely processing and processing the data they have, can they correctly evaluate their own production and operation conditions and quickly make production adjustments. The data owned by companies is growing at an incredible rate. If companies cannot study these data that can change at any time in time, it will seriously affect their own development.

\subsection{Insufficient Understanding of the Role of Data Research in Decision-Making}

Data analysis makes business decisions for the person in charge of the enterprise. Data analysis plays an extremely important role in the process of enterprise investment decision, marketing decision and management decision. The arrival of various data, structured data, and 
semi-structured data in the era of big data, But most companies still can't analyze and study the advantages of their own business in the future, changes in customer demand, etc. Business managers cannot make good use of big data to help companies make correct decisions.

4.4 The Management Model of Cross-Border B2B Foreign Trade Export Enterprises is Difficult to Adapt to the Changes Brought about by Big Data

My country's cross-border B2B foreign trade export supply chain mainly has operating modes such as "general export", "direct mail export" and "special regional export". Among them, "general trade export" refers to domestic export companies conducting $\mathrm{O} 2 \mathrm{O}$ transactions with foreign customers through third-party B2B cross-border e-commerce platforms. Domestic export companies submit customs clearance applications to the government's public service departments, accept inspection, quarantine, approval, and supervision, carry out mass customs clearance of commodities, and then apply for tax refunds to the government. After foreign customers obtain goods through cross-border logistics service providers, they are sold to final consumers through the local distribution network. "Direct mail export" means that domestic export companies directly sell products to foreign consumers through a third-party B2C cross-border e-commerce platform or through the export company's self-built B2C cross-border e-commerce platform. Special areas are divided into bonded areas and export processing areas; special customs supervision areas include bonded areas, export processing areas, bonded logistics parks, cross-border industrial parks, bonded port areas, and comprehensive bonded areas. When carrying out cross-border e-commerce "special area export" business, it is necessary to file with the cross-border e-commerce platform in advance; goods entering the special customs supervision area shall be managed by account books; goods leaving the zone shall be sent to the customs service platform "export commodity declaration" List" electronic data. Problems in the management of cross-border B2B foreign trade export companies: 1. The brand competitiveness of cross-border e-commerce companies is not strong. My country's cross-border e-commerce B2B export products are still at the lower end of the division of labor. They are mainly based on OEM and processing materials. They are at the bottom of the "smiling curve" of the supply chain. They have no brand qualifications, homogenization of products, and excessive price wars. Ignoring the construction of brand, quality, and service awareness will inevitably lead to the lack of success in the development of cross-border e-commerce. It has become a common problem faced by small and medium-sized cross-border e-commerce sellers in my country. These products are highly substitutable and lack a true global market. Competitiveness. 2 The supply chain cooperation mechanism is not sound. The node enterprises in the structure of the supply chain of Chinese enterprises have realized that only through supply chain management can they achieve punctual and appropriate amounts in procurement, transportation, storage, production, processing, distribution, sales and 
other links in order to reduce inventory and reduce operating costs. Improve competitiveness. My country's enterprise supply chain management is in its infancy. The supply chain cooperation relationship lacks long-term and stability. The design of enterprise production and management systems does not consider the impact of the supply chain, lacks a complete credit evaluation system, and has not formed information sharing and risk sharing. The cooperative mechanism of responsibility is contrary to the principle of coordination of supply chain benefits in terms of profit distribution.3. Insufficient data sharing and application of supply chain information. In the context of cloud computing and big data, export companies have to pay a high price to obtain transaction data, potential demand information and customer information mastered by cross-border e-commerce platforms, which make it impossible for companies to truly use big data and other information technologies to analyze market conditions, And cannot provide favorable conditions for the business decision-making of enterprises. 4 Cross-border logistics is lagging behind [10]. At present, there are many problems in my country's cross-border logistics: First, it is the problem of high cost. High logistics costs have become the biggest "bottleneck" problem faced by cross-border transactions. Second, the cross-border logistics system is underdeveloped, and a complete e-commerce logistics supply chain system has not been formed. In the entire supply chain system such as information flow, capital flow, logistics, and user flow, cross-border logistics is at the core link, but the reality is that logistics is not integrated into the entire system, or even separated from other links.

\section{IN THE CONTEXT OF BIG DATA, WITH THE HELP OF ENTERPRISE SUPPLY CHAIN MANAGEMENT MODE, INNOVATE STRATEGIES FOR CROSS-BORDER B2B FOREIGN TRADE EXPORT ENTERPRISES TO COPE WITH CHALLENGES}

The relatively backward management system and operating methods formed for a long time are seriously restricting the survival and development of foreign trade export enterprises under the new situation. Enterprises based on the supply chain management model innovate a new management idea and management for cross-border B2B foreign trade exports. Mode, from the organization to the management mode for all-round optimization and transformation, thereby improving the enterprise's management level and enhancing core competitiveness [11]. At present, foreign trade export enterprises are facing increasingly severe market competition and various challenges from home and abroad. In order to overcome many difficulties and enhance the core competitiveness of B2B foreign trade export enterprises. Utilize a supply chain management system that adapts to changes in the market environment and is a new management model based on modern information technology.

\subsection{Characteristics of Supply Chain Management}


The supply chain management system is referred to as the SCM system for short, and its operation mode mostly refers to the reasonable arrangement of various resources from material procurement to product sales, and realizes the participants in the supply chain, such as suppliers, manufacturers and all other members Collaborative online management system. The supply chain management system can effectively form an integrated management or share the operation process and information of each link, thereby realizing the visualization and informationization of management, and improving the overall operation efficiency.

The characteristics of the supply chain management system are as follows.

Feature 1: The complexity of the supply chain management system. The supply chain management system covers the management of customer resources, channel resources and other functions. It can also provide a variety of functional components to maximize the satisfaction of different industries and enterprises. Business requirements enable companies to achieve efficient and collaborative business operations.

Feature 2. Supply chain management regards all node enterprises as a whole and realizes the strategic management of the whole process. The supply chain is a network structure composed of suppliers, manufacturers, distributors, sellers, customers and service providers. Supply chain management integrates the management of logistics, information flow, capital flow, business flow and value flow throughout the entire supply chain. All node companies are required to realize information sharing, risk sharing, and benefit coexistence, and to understand the importance and necessity of supply chain management from a strategic perspective, so as to truly realize overall effective management.

Feature 3: Focus on buyers to meet customer needs as the core. The new characteristics of market competition in the information age have prompted companies to shift from focusing on the seller's perspective to focusing on the buyer. Customers are the starting point of the entire supply chain's capital flow, and customer satisfaction is the common goal of all companies in the supply chain.

Feature 4: Supply chain management can scientifically reduce the purchase cost and transaction cost between enterprises, which is beneficial to increase the income and profit of the enterprise. The supply chain management system also has the characteristics of rapid response, which can reduce the order processing time in the supply chain and increase the order processing and fulfillment rate. The supply chain management system can improve the business processing process, reduce the procurement cost, and stabilize the supply chain in the medium and long term. The cooperative partnership allows both parties to benefit more. The supply 
chain management system reduces the purchase cost and transaction cost between enterprises, which is conducive to increasing the income and profit of the enterprise.

Feature 5. Supply chain management can effectively integrate scattered suppliers and complex products, with the goal of maximizing the value of the entire supply chain. Supply chain management treats all enterprises in the supply chain as a whole, covering the comprehensive management of logistics, capital flow and information flow, and pays attention to the coordination and integration of all enterprises for common goals, so as to maximize the value of the entire supply chain. Target. This is a new concept of cooperation and competition. It not only considers the internal management of the core enterprise, but also pays more attention to the utilization and cooperation of resources in each link in the supply chain, and ultimately achieve a "win-win".

Feature 6, supply chain management has a brand-new inventory concept. Traditional inventory thinking believes that inventory is a necessary measure to maintain production and sales, and it is a necessary cost. Therefore, supply chain management enables companies and their upstream and downstream companies to realize the transfer of inventory in different market environments, and reduces the company's inventory costs. It can reduce the backlog of inventory and increase the inventory sales rate and capital turnover rate. This also requires various corporate members in the supply chain to establish strategic partnerships to reduce the total cost of inventory through rapid response.

5.2 Build a Supply Chain Platform with the Help of Enterprise Supply Chain Management Advantages

In the national standard of logistics terminology issued by my country in 2001, the definition of supply chain refers to "the network chain structure formed by upstream and downstream enterprises involved in the activities of providing products and services to end users in the process of production and circulation." Supply chain is a life cycle process that supports logistics, information flow, capital flow, and knowledge flow to transfer products and services from suppliers to customers. The supply chain is a network that includes equipment and distribution options. The functions of this network are: purchasing raw materials, transforming raw materials into semi-finished products or finished products, and delivering finished products to customers. Supply chain is a network composed of many organizations connected by upstream and downstream. These organizations participate in many different processes and activities, and the purpose of these processes and activities is to produce value in the form of products or services. 
Participate in strategic cooperation and information sharing between enterprises through the supply chain of suppliers, manufacturers, distributors, retailers, warehouses, and end customers. Through integrated management of product raw material supply, processing and assembly, distribution and distribution, etc., Coordinate and control the logistics, capital flow and information flow throughout the supply chain, so as to realize the goals of enterprises participating in the supply chain to reduce risks, improve competitiveness, and profit together.

5.3 Optimize the Supply Chain Structure by Leveraging on the Advantages of Enterprise Supply Chain Management

The structure of the supply chain is a network composed of independent or semi-autonomous enterprises, which mainly include suppliers, manufacturers, distributors, warehouses, retailers, and so on. In every supply chain, there is often a core company, which can be a manufacturing company or a retail company. For core enterprises, the supply chain is a network chain that connects its suppliers, their suppliers, and users and users. Each link of the supply chain has a corresponding relationship between the supplier and the demander. Therefore, the supply chain involves multiple interrelated but legally independent companies and organizations. It is a value-added network that takes a certain company as the core to meet customer needs, avoid the risks of participating companies in the supply chain, and enhance the value of supply chain participating companies.

Along with the flow of logistics, capital flow and information flow in this network, the core enterprise and other enterprises in the supply chain jointly undertake the procurement, production and final delivery of products related to one or more types of products. Various activities. How to conduct scientific management of the node enterprises in the supply chain structure. Supply chain management refers to the integration of a series of value-added products, services and information processes from raw material suppliers to customers; supply chain management is no longer just pure production, sales, supply and Enterprise alliances, but to further improve cooperative relations, make the operating procedures in the supply chain more reasonable and flexible to obtain competitive advantages that cannot be replaced in the fluctuations of the industrial environment; supply chain management includes All planning and management activities and all logistics management activities of the process, including coordination and collaboration with channel partners, involving suppliers, intermediaries, third-party service providers and customers, in essence, supply chain management It is the integration of supply and demand management within and between enterprises.

In short, the realization of supply chain management is to link all nodes and enterprises in a supply chain, such as suppliers, manufacturers, distributors, retailers, etc., to optimize, so that 
the means of production can pass through production, The distribution link becomes value-added products, which are delivered to consumers with consumer demand. Supply chain management can effectively eliminate duplication, waste and uncertainty, reduce total inventory, and create competitive cost advantages.

5.4 With the Help of the Enterprise Supply Chain Management Model, Innovate the Strategies of Cross-Border B2B Foreign Trade Export Enterprises to Cope with Challenges

Vigorously cultivate international brands of cross-border e-commerce and establish strategic alliances of international brands

At present, the brand influence of cross-border e-commerce companies is low, and some products are severely homogenized. They have no brand awareness and only fight for prices. Cross-border e-commerce companies are mainly traders. They do not engage in $R \& D$, production, or branding. They just sell factory products abroad and act as commodity "porters". Clarify brand product positioning, develop and design products and services that meet the needs of foreign consumers, strive to improve brand product quality and service levels, and establish a good quality and image of the brand.

Innovative network marketing model, using marketing-based website optimization, brand marketing innovation: the purpose of starting a business is to make consumers accept the corporate culture, improve the market acceptance of products and consumer recognition. Therefore, brand marketing in the context of the era of big data is even more important. In the marketing process, the corporate culture should be emphasized. Whether a company's product can become a well-known product is determined to a large extent by the company's marketing policy. Therefore, strengthening the management model of brand marketing in the context of the era of big data is to adapt to the development of the times and will also expand a broader world for the development of enterprises. Use marketing-based website optimization, SEM search engine marketing, forum marketing, ad-post marketing, blog marketing, word-of-mouth marketing and other online marketing methods to expand the international reputation of products, independently master overseas marketing channels, and accelerate the cultivation of cross-border e-commerce international brands.

Establish industry development alliances, vigorously support brand building strategic alliances for cross-border e-commerce companies, and guide companies to make overall recommendations in the form of alliances and supply chain integration to form a "group-style" development of "learning from each other's strengths, complementing each other's strengths, collaboration and sharing, and resource integration" The idea is to enhance the ability to accept 
orders, the ability to resist risks, and the international influence, so as to enhance the brand awareness of "Made in China" and build a strong source of export cross-border e-commerce supply chain. On the one hand, for small and unbranded manufacturing companies, organize companies with overseas brand building capabilities to create "shared brands" and provide brand authorization portfolio services. Brand authorization companies are responsible for quality control and after-sales, which will greatly increase the profit of small companies. . On the other hand, for manufacturing companies that focus on promoting their own brands, a series of industry chain support policies have been introduced, including product design, product planning, brand promotion and market promotion. Introduce local online marketing teams in Europe and the United States to cooperate with companies to provide companies with a full range of cross-border e-commerce agency operations and other brand promotion services, and assist a group of companies with independent brand awareness and design capabilities that can represent the advanced level of Chinese manufacturing to go global, Occupy the mainstream market in Europe and America.

\subsection{Relevant Countermeasure Suggestions and Construction Plan}

(1) Outside the supply chain: The construction of a cross-border e-commerce supply chain platform also relies on the protection of external related mechanisms, mainly focusing on the relationship between the government and financial institutions and the cross-border e-commerce supply chain. On the one hand, in order to ensure the smooth operation of its capital flow, cross-border e-commerce can cooperate with relevant financial institutions to attract investment, ease the pressure on supply chain funds, and develop financial products such as consumer credit guarantees based on the supply chain. Based on big data, financial institutions analyze the credit ratings of cross-border e-commerce companies to provide a basis for investment and loan decisions. On the other hand, the government has increased its policy support for cross-border e-commerce, approved the establishment of bonded areas, realized bonded storage, and built a transfer base for cross-border e-commerce foreign trade, greatly reducing the logistics and warehousing costs of cross-border e-commerce, and shortening foreign trade. Logistics time, thereby improving the efficiency of international trade import and export, and improving the service level of cross-border e-commerce. The current government's welfare policy on e-commerce has also attracted overseas e-commerce companies to set up overseas warehouses in the bonded zone, which greatly facilitates domestic logistics and distribution. Based on big data analysis, the government timely grasps the trade trends of cross-border e-commerce, formulates targeted policies, regulates market order, and escorts the sustainable development of cross-border e-commerce. The government, cross-border e-commerce and financial institutions should coordinate and cooperate to build my country's cross-border e-commerce credit system, establish standardized standards, improve corporate 
credit ratings, and increase international credibility.

(2) Inside the supply chain: The main body of the supply chain includes upstream production suppliers, cross-border e-commerce, logistics companies, and target customers. The flow of information forms big data resources. The key to the construction of a supply chain platform is to analyze the big data in trade. Obtain useful information. These useful information include: 1. Data on the transactions between upstream suppliers in the supply chain and target consumers; 2. Data on transactions between cross-border e-commerce and upstream suppliers; 3. Cross-border e-commerce, target consumers and logistics Company data. Upstream production suppliers use Internet information technology to collect, integrate, and analyze target customers' consumption preferences and purchase information and other data, in-depth excavation of customer needs, so as to segment the market, provide customers with personalized services, and continuously improve based on consumer feedback. Update products and services, respond to changes in market demand in a timely manner, and improve the issue of product homogeneity; cross-border e-commerce and suppliers form collaboration to share information to achieve symmetry of market information between the two parties, and cross-border e-commerce timely analyzes customer needs from suppliers Reflect, and analyze the potential consumption needs of target customers through data mining, timely feedback information to suppliers, promote the development of new products by suppliers, and increase customer stickiness; consumers evaluate logistics service orders and feedback their service quality to e-commerce companies. E-commerce companies use this to analyze their purchasing, storage and transportation conditions, and share the analysis results of logistics service information with logistics companies to discover problems in logistics links in time, collaborate in depth, propose logistics service optimization plans, and reduce storage costs. Improve logistics efficiency and enhance consumer experience. When constructing a cross-border e-commerce logistics export model, consider building border warehouses in the bonded area; for the import model, you can analyze target customer behavior data and store goods in the bonded area in advance, which will achieve the improvement of logistics operation efficiency and service quality. Cross-border e-commerce uses big data analysis technology to accurately grasp market demand, so that warehousing management is refined and logistics costs are reduced. Agglomeration of cross-border e-commerce free trade zone logistics will improve the management level, form economies of scale, and then build my country's high-end logistics brand.

(3) Establish an overseas after-sales service system network

By coordinating the acquisition of foreign enterprises such as after-sales service providers and large retailers by state-owned enterprises, or supporting leading enterprises to set up 
professional after-sales service companies abroad, we can provide domestic cross-border e-commerce enterprises with customs clearance, supporting maintenance, returns and exchanges, call centers, etc. Improve the after-sales service system of logistics services, enhance the localization experience of cross-border e-commerce products, and create a cross-border e-commerce industry system with a full chain of domestic production-foreign sales-foreign services.

(4) Improve corporate overseas compliance services

Compliance is a pre-recommended incentive policy for companies' overseas operations. It supports talents who are familiar with European and American laws, policies, and e-commerce rules to create professional overseas compliance service providers, and provides certifications, patents, taxation, customs, laws, etc. from various countries for companies traveling overseas. Services to help domestic manufacturing industries identify potential compliance risks and avoid risks. At the same time, increase the training and introduction of foreign-related legal service talents, establish a foreign-related legal service talent pool, and actively guide foreign-related law firms to in-depth cooperation with cross-border e-commerce associations and cross-border e-commerce companies to provide professional escorts for corporate exports.

\section{(5) Home and abroad}

On the one hand, support cross-border e-commerce service companies and supply chain companies to establish overseas cross-border e-commerce clusters to provide domestic cross-border e-commerce companies with joint office space and warehousing services; on the other hand, accelerate the promotion of domestic cross-border e-commerce integration The construction of carrier platforms such as pilot zones, the establishment of cross-border e-commerce service networks such as warehousing, logistics, payment, and operations, the construction of overseas local after-sales and compliance services, and the completion of overseas localization; improve brand awareness, accelerate the formation of industrial clusters, and build cross-border e-commerce Businesses develop the industrial chain and ecological circle, and accelerate the formation of a "dual cycle" pattern at home and abroad.

(6) Accelerate the construction of overseas online and offline channels

Deploy Chinese brand experience stores in important cities around the world, build overseas $\mathrm{O} 2 \mathrm{O}$ experience stores through acquisition of overseas chain stores, leases, etc., or cooperate with Walmart, Target, Costco and other giant offline supermarkets to build overseas cross-border e-commerce $\mathrm{O} 2 \mathrm{O}$ experience stores, which will be offline Combining experience 
and online sales, opening up online and offline channels, and providing overseas platforms for domestic manufacturing companies to go overseas. At the same time, strengthen cooperation with TV shopping platforms with tens of millions of fans in Europe and the United States, such as QVC, HSN, etc., to greatly increase the popularity of overseas cross-border e-commerce $\mathrm{O} 2 \mathrm{O}$ experience stores and strengthen overseas sales capabilities.

\section{CONCLUSION}

The advent of the era of big data marks that the development of various industries has gradually entered a new stage. This article analyzes the current development of cross-border e-commerce in the context of the era of big data: product homogeneity, logistics, customs clearance and foreign exchange settlement, etc., to achieve cross-border e-commerce The further development of suppliers must build a complete supply chain platform. Cross-border e-commerce must firmly grasp the core big data information resources, realize the coordination and cooperation of internal suppliers, cross-border e-commerce, logistics companies and consumers in the supply chain, promote the virtuous circle between capital flow, commodity flow and logistics, and recognize at the same time The government and financial institutions play an important role in the development of cross-border e-commerce. In the context of big data, with the help of the enterprise supply chain management model, we continue to explore effective ways to optimize the supply chain platform, constantly respond to market demand, and innovate cross-border B2B foreign trade export corporate strategies, so that big data can further exert its ability to promote the development of my country's foreign trade.

\section{REFERENCES}

[1] Wu HQ. Seeking Truth, Opportunities and Challenges in the Big Data Era, 2013.

[2] Wen YB. Research on the innovation of enterprise management mode under the background of big data era. Modern Business, 2017, (25).

[3] Meng J, Geng G In the era of big data, opportunities? Challenge?. China New Times, 2012.

[4] Wang YL. Research on customer development of my country's foreign trade enterprises under the background of big data. Foreign Economic Relations and Trade, 2016, (12)

[5] Lu ZQ. The status quo and operation mode of my country's cross-border e-commerce logistics. Bohai Economic Outlook, 2018, (11).

[6] Chen FJ, Li ZG. E-commerce and enterprise supply chain management. Modern Enterprise, 2011, (12).

[7] Yao Q. B2B e-commerce and enterprise supply chain management. Science and Technology Information (Academic Research), 2007, (8).

[8] Dong BW. Discussion on the connection of cross-border e-commerce logistics and e-commerce platform. Business Economics, 2018, (11).

[9] Yue X. B2C-based cross-border e-commerce export logistics model development and strategy analysis. China Logistics and Purchasing, 2018. 
[10] Jiang RR. Research on the realization path of cross-border e-commerce and logistics collaboration under the background of Internet +. Taxation 2018, (19).

[11] Tao YQ. Research on flexible optimization strategy of supply chain of my country's cross-border e-commerce. Reform and Strategy 2017, 33 (08). 